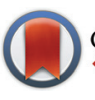

CrossMark $\leftarrow$ click for updates

Cite this: Polym. Chem., 2015, 6 , 3074

Received 8th December 2014 Accepted 5th March 2015

DOI: $10.1039 / c 4 p y 01700 e$ www.rsc.org/polymers

\title{
Upper or lower critical solution temperature, or both? Studies on cationic copolymers of $\mathrm{N}$-isopropylacrylamide $\uparrow$
}

\author{
Erno Karjalainen, Vladimir Aseyev and Heikki Tenhu*
}

\begin{abstract}
The solution properties of statistical copolymers of N-isopropyl acrylamide (NIPAm) and cationic (3-acrylamidopropyl) trimethylammonium chloride (AMPTMA) have been studied. The phase behavior of the copolymers in aqueous solutions is strongly affected by the addition of lithium bis(trifluoromethane)sulfonimide $\left(\mathrm{LiNTf}_{2}\right), \mathrm{NaCl}$, or both. Hydrophobic $\mathrm{NTf}_{2}$ counter ions bind to the AMPTMA repeating units. By adjusting the balance between hydrophobic and electrostatic interactions the transition temperature of the copolymers may be tuned over a wide temperature range. It was observed that a homopolymer PAMPTMA undergoes an UCST-type phase separation in an aqueous solution in the presence of both $\mathrm{NaCl}$ and $\mathrm{LiNTf}_{2}$. When AMPTMA and NIPAm are present in the copolymer in nearly equal amounts both LCST and UCST can coexist. It was observed that the effect of $\mathrm{LiNTf}_{2}$ is similar to that of the salts in the kosmotropic end of the Hofmeister series for PNIPAm.
\end{abstract}

\section{Introduction}

A well-known method to change the phase separation temperature of an aqueous thermoresponsive polymer as PNIPAm is to copolymerize hydrophilic or hydrophobic units to the chain. This report discusses a further step taken to alter the solubility of cationic copolymers of $N$-isopropylacrylamide.

Poly( $N$-isopropyl acrylamide) (PNIPAm) is by far the most studied thermoresponsive polymer. ${ }^{1}$ Since the original report of 1968, the lower critical solution temperature (LCST) of PNIPAm in water has been a subject of numerous publications. $^{2,3}$ The cloud point $\left(T_{\mathrm{c}}\right)$ is approximately $32^{\circ} \mathrm{C}$, though this slightly varies with the concentration and molecular weight at low degrees of polymerization. ${ }^{3-6}$ The cause of the phase separation at the cloud point is the change of water from a good solvent to a poor one, which is manifested as a decrease in the second virial coefficient $\left(A_{2}\right)$ and leads to a coil-to-globule-transition. ${ }^{7}$ In very dilute solutions, the globules are stable, but a higher concentration leads to the formation of stable mesoglobules. ${ }^{8}$

Laboratory of Polymer Chemistry, Department of Chemistry, University of Helsinki, P.O. Box 55, 00014 Helsinki, Finland. E-mail: heikki.tenhu@helsinki.fi

$\dagger$ Electronic supplementary information (ESI) available: NMR-spectra, definitions of the cloud points, representative transmittance as a function of temperature curves, $T_{\mathrm{cL}}$ as a function of $\mathrm{LiNTf}_{2}$ concentration for CP-8 and CP-26, effect of polymer concentration on $T_{\mathrm{cL}}$ and $T_{\mathrm{cU}}$, representative micro-DSC-thermograms, and figures on the effect of heating rate on reversibility of the transitions. See DOI: $10.1039 / \mathrm{c} 4 \mathrm{py} 01700 \mathrm{e}$
At the cloud point, the polymer chains dehydrate and new intra- and intermolecular hydrogen bonds are formed. ${ }^{9-11}$ In particular the breaking of the hydration layer or "water cage" around the isopropyl groups plays a central role. ${ }^{12}$ However, even above $T_{\mathrm{c}}$, the polymer globules are still hydrated and a large majority of the amide groups keep hydrogen bonded to water. ${ }^{8,10,13-15}$ The transition takes place in domains, or "cooperative units", which dehydrate as a whole. ${ }^{16,17}$ These domains consist only of a part of the chain in a high molecular weight PNIPAm, but the whole chain acts as one in the case of a low molecular weight polymer. ${ }^{17}$ Thermodynamically, the driving force behind the LCST phenomenon can be understood to be the gain in entropy caused by the release of the bound water to the bulk. ${ }^{18-20}$ The enthalpy of the transition is endothermic. ${ }^{9,16,21}$

The system is partially reversible on cooling, but not all newly formed hydrogen bonds break during cooling, which is seen as hysteresis. ${ }^{22,23}$ Breaking the new intrachain hydrogen bonds is observed, when PNIPAm solution is kept at low temperature for a long time. ${ }^{23}$ The dissolution process has also calorimetrically been found to be slow, especially when the PNIPAm solution has been kept at temperatures above $T_{\mathrm{c}}$ for a long time. ${ }^{24}$ The redissolution of PNIPAm happens in two exothermic steps, which are believed to correspond to the dissolution of the shell and the core of the formed structure. ${ }^{25}$

Some salts, e.g. NaI and NaSCN, may increase the $T_{\mathrm{c}}$ of PNIPAm at low concentrations. However, generally the addition of salts to an aqueous solution of PNIPAm decreases the $T_{\mathrm{c}}{ }^{9,26,27}$ The magnitude of this effect follows the 
Hofmeister series and is more related to the anion than to the cation of a given salt. ${ }^{26,27}$ The effect has been attributed to a change of surface tension at the polymer-water interface, polarization of water, and anion bonding to the amide groups of PNIPAm. ${ }^{27-30}$ According to another view, the effect arises from binding of the cation to the amide oxygen of PNIPAm. ${ }^{31}$ The strength of this interaction is then modulated by the anion. The enthalpy of transition is slightly less endothermic when ions are introduced, which may be due to an exothermic contribution arising from the hydration of the ions. ${ }^{19}$ Ways to influence the $T_{\mathrm{c}}$ of a PNIPAm homopolymer also include the end-groups, ${ }^{5,6,32-34}$ tacticity, $^{34-36}$ and the addition of cosolvents. $^{37,38}$

Copolymerization also influences the $T_{\mathrm{c}}$. Hydrophilic comonomers increase the $T_{\mathrm{c}}$ and hydrophobic comonomers decrease it. ${ }^{39-44}$ This is due to the fact that the overall hydrophobicity of the polymer determines the entropic gain associated with the dehydration of the chains. ${ }^{19}$ Enthalpy of the transition decreases linearly as a function of $T_{\mathrm{c}}$ when a more hydrophilic comonomer is introduced, regardless of the nature of the comonomer. ${ }^{19,39,45,46}$ The strength of hydrogen bonding between water molecules in the hydration layer is lower at elevated temperatures and therefore the decrease in enthalpy is caused by an increase in the $T_{\mathrm{c}}{ }^{19,39,46}$ Another factor affecting the $T_{\mathrm{c}}$ is the incomplete dehydration induced by the hydrophilic groups. ${ }^{45}$ Analogously, incorporation of hydrophobic comonomers increases the enthalpy of transition. ${ }^{39}$ The finding is in accordance with the view that differences in the strength of hydrogen bonding between water molecules are responsible for the differences in enthalpy. ${ }^{19}$

Bokias et al. studied random copolymers of PNIPAm and acrylic acid. ${ }^{47}$ They found out that a copolymer with a PNIPAm content of $17.5 \mathrm{~mol} \%$ as a $10 \mathrm{mg} \mathrm{mL}^{-1}$ solution has not only a LCST type of $T_{\mathrm{c}}$, but also an upper critical solution temperature (UCST) type of $T_{\mathrm{c}}$ at high temperature. This is possible in a $\mathrm{NaCl}$ solution in the concentration range of 0.15 to $0.4 \mathrm{M}$. This is probably the only example of a PNIPAm containing a random copolymer with a soluble-insoluble-soluble behaviour with increasing temperature. Some examples of other copolymers with such behaviour in aqueous systems exist, however. ${ }^{48-50}$

Bis(trifluoromethane)sulfonimide $\left(\mathrm{NTf}_{2}\right)$ is known to turn many polycations insoluble in water. ${ }^{51}$ This anion was recently used to modify the thermal response of a weak polycation, poly(2-(dimethylamino) ethyl methacrylate) (PDMAEMA). ${ }^{52}$ Also, the introduction of $\mathrm{NTf}_{2}$ to solutions of two different polycations triggered UCST-type behaviour, provided that the overall ionic strength of the solution was sufficiently high. ${ }^{53}$ The present study develops these ideas further using copolymers of NIPAm and cationic (3-acrylamidopropyl)trimethylammonium chloride (AMPTMA) with various monomer ratios. Such polymers should respond not only to ionic strengths but also to low concentrations of $\mathrm{NTf}_{2}$. Other investigators have shown that it is possible to influence the $T_{\mathrm{c}}$ of analogous polymers by ionic strength. ${ }^{48-50,54}$ By introducing a hydrophobic anion and simultaneously changing the ionic strength with a simple salt it should be possible to change the thermal response of the copolymers over a wide range of temperatures.

\section{Experimental}

\section{Materials}

Ethyl 2-chloropropionate (EClPr) (Aldrich, 97\%) and dimethyl formamide (DMF) (Lab-Scan, HPLC-grade) were distilled in a vacuum. Tris(2-dimethylaminoethyl)amine ( $\left.\mathrm{Me}_{6} \mathrm{TREN}\right)$ was synthesized as reported earlier. ${ }^{55}$ (3-Acrylamidopropyl)trimethylammonium chloride (AMPTMA) (Aldrich, 75 w\% solution in water) was precipitated and thoroughly washed with acetone and dried in a vacuum. Water used to prepare polymer solutions, salt solutions and samples was purified with ELGA purelab ultra-purification system to obtain conductivity of $0.05-0.07 \mu \mathrm{S} \mathrm{cm}^{-1}$. Water used in syntheses was distilled. $\mathrm{N}$-isopropyl acrylamide (NIPAm) (Acros Organics, 99\%) was recrystallized from hexane. $\mathrm{CuCl}$ (Aldrich, 99.995\%), $\mathrm{CuCl}_{2}$ (Aldrich, 99.999\%), lithium bis(trifluoromethane)sulfonimide (LiNTf ${ }_{2}$ ) (Aldrich, 99\%), NaCl (Fluka, 99\%), and hexane (VWR, HPLC-grade) were used as received. Deuterated solvents were obtained from Euriso-top and used as received.

\section{Polymerizations}

All the polymerizations were conducted with atom transfer radical polymerization (ATRP). ${ }^{56}$ In the polymerizations ethyl 2-chloropropionate (ECIPr) was used as the initiator (I). All of the studied copolymers were synthesized with reagent ratios $([\mathrm{NIPAm}]+[$ AMPTMA $]):[\mathrm{EClPr}]:[\mathrm{CuCl}]:\left[\mathrm{CuCl}_{2}\right]:\left[\mathrm{Me}_{6} \mathrm{TREN}\right]$ of $100: 1: 0.8: 0.2: 1$. Polymerizations were conducted with a total monomer concentration of approximately $2 \mathrm{M}$ in $1: 1$ (vol.) water-DMF-mixture at $25{ }^{\circ} \mathrm{C}$ for 4 hours. The PNIPAm homopolymer (PNIPAm-1) was synthesized without $\mathrm{CuCl}_{2}$, with a relative [CuCl] of 1 and a reaction time of 3 hours, but the procedure was otherwise the same as in the case of copolymers. The PAMPTMA-homopolymer (PAMPTMA-1) was synthesized similarly as the copolymers, but with a relative [AMPTMA] of 50 .

One of the polymerizations is described below (CP-17), other polymerizations were conducted similarly. Also other methods were used, but they did not produce satisfactory results. These polymers were used to examine the randomness of the copolymerization (see Results and discussion).

NIPAm (2.2703 g, $20.1 \mathrm{mmol}), \mathrm{CuCl}(0.0198 \mathrm{~g}, 0.200 \mathrm{mmol})$, $\mathrm{CuCl}_{2}(0.0067 \mathrm{~g}, 0.0498)$ and AMPTMA (1.0438 g, $\left.5.05 \mathrm{mmol}\right)$ were dissolved in $6 \mathrm{~mL}$ of water and $4 \mathrm{~mL}$ of DMF. A zerosample was taken at this point and analysed later with NMR. The mixture was bubbled with nitrogen for 15 minutes, after which $\mathrm{Me}_{6}$ TREN (0.0579 g, $0.251 \mathrm{mmol}$ ) in $1 \mathrm{~mL}$ of DMF was added. The mixture was bubbled with nitrogen for 45 minutes. EClPr $(0.0340 \mathrm{~g}, 0.249 \mathrm{mmol})$ in $1 \mathrm{~mL}$ of DMF, which was also bubbled with nitrogen for 45 minutes, was then added using a nitrogen-flushed syringe. The reaction was allowed to proceed in a bath thermostated to $25^{\circ} \mathrm{C}$. 
After 4 hours reaction time, the reaction was quenched by freezing the reaction flask with liquid nitrogen and opening it to the atmosphere. After melting, a sample was taken and analysed later with NMR. In order to oxidize all the possibly remaining, sparingly soluble, $\mathrm{CuCl}$, water was added to the flask and the mixture was stirred under air for 30 minutes. Next, the reaction mixture was moved to a dialysis bag (molecular weight cutoff $3500 \mathrm{~g} \mathrm{~mol}^{-1}$ ) and dialysed against water for 5 days with 5 water changes. The product was then recovered by freeze-drying the contents of the dialysis bag.

\section{Characterization}

Size exclusion chromatography (SEC). Two methods were used in the SEC measurements. In the first one, the system consisted of a Waters 515 HPLC-pump, Waters Styragelcolumns and Waters 2410 refractive index (RI) detector. The SEC measurements were run in DMF containing $1 \%$ of $\mathrm{LiBr}$ and calibrated using poly(methyl methacrylate) standards. The PNIPAm-1 homopolymer sample was prepared just by dissolving the sample in the eluent. The samples containing AMPTMA were prepared by first dissolving the polymers in methanol. Then $\operatorname{LiNTf}_{2}$ was added as a $100 \mathrm{mg} \mathrm{mL}^{-1}$ solution in methanol in such an amount that the mass of salt was 2.5fold the mass of the polymer. Methanol was then removed in a vacuum and the residue was dissolved in the eluent in a polymer concentration of $4 \mathrm{mg} \mathrm{mL} \mathrm{m}^{-1}$, which corresponds to the $\operatorname{LiNTf}_{2}$ concentration of $10 \mathrm{mg} \mathrm{mL}^{-1}$.

In the second method the system consisted of a Waters 515 HPLC pump, Waters Ultrahydrogel columns and Waters 2410 refractive index (RI) detector. The samples were run in $0.8 \mathrm{M}$ aqueous $\mathrm{NaNO}_{3}$ with $3 \%$ of acetonitrile. The system was calibrated with poly(ethylene oxide) standards. The samples were prepared by mixing the polymer and eluent to a polymer concentration of $4 \mathrm{mg} \mathrm{mL} \mathrm{m}^{-1}$ and allowing the samples to dissolve under refrigeration overnight.

Sample preparation. For all measurements of the thermoresponsive properties the samples were prepared in a similar fashion. Polymer stock solutions with a concentration of $10 \mathrm{mg} \mathrm{mL} \mathrm{mL}^{-1}$ were prepared by dissolving $0.2000 \mathrm{~g}$ of the polymer in water and diluting it to a volume of $20 \mathrm{~mL}$ in a volumetric flask. The solutions were shaken at room temperature overnight and stored refrigerated for a minimum of 24 hours before any sample preparation. All solutions needed in sample preparation were used as fridge-cold. The possible salt solutions were always added to the sample vial first, then water and finally the polymer while continuously stirring the solution. As an example, a solution with $\mathrm{LiNTf}_{2}$ concentration of $10 \mathrm{mM}$, NaCl concentration of $500 \mathrm{mM}$ and polymer concentration of $1 \mathrm{mg} \mathrm{mL} \mathrm{m}^{-1}$ was made as follows: $30 \mu \mathrm{L}$ of $1 \mathrm{M}$ $\operatorname{LiNTf}_{2}, 300 \mu \mathrm{L}$ of $5 \mathrm{M} \mathrm{NaCl}$ and $2370 \mu \mathrm{L}$ of water were added to a vial with a micropipette. Then the solution was stirred vigorously and $300 \mu \mathrm{L}$ of $10 \mathrm{mg} \mathrm{mL}^{-1}$ solution of the polymer was added. In most cases, the polymer concentration was kept at $1 \mathrm{mg} \mathrm{mL}^{-1}$.

Transmittance measurements. Transmittance as a function of temperature was measured with a JASCO J-815 CD spectro- meter equipped with a PTC-423S/15 Peltier type temperature control system. The transmittances of the samples were monitored at wavelength $600 \mathrm{~nm}$. The sample cuvettes were degassed in a vacuum at $5{ }^{\circ} \mathrm{C}$ prior to measurements. The temperature was controlled with the sample holder, but the reported temperatures were measured directly from the sample. All of the heating and cooling scans were conducted at the rate of $1^{\circ} \mathrm{C} \mathrm{min}^{-1}$.

The experiments were typically conducted by heating the sample holder from $5^{\circ} \mathrm{C}$ to $90^{\circ} \mathrm{C}$, with an initial stabilization period of 10 minutes at $5{ }^{\circ} \mathrm{C}$. Also a cooling cycle from $90{ }^{\circ} \mathrm{C}$ to $5{ }^{\circ} \mathrm{C}$ was usually measured, with 10 minutes of stabilization at the starting temperature. In some cases, the heating and cooling scans were done in succession. In these measurements, the first scan was always the heating scan. The effect of the cooling rate was in some cases tested by cooling the sample, after the initial heating run, from $90{ }^{\circ} \mathrm{C}$ as fast as possible (in approximately five minutes) to $5{ }^{\circ} \mathrm{C}$. Then, the sample was heated for the second time as described above.

Differential scanning microcalorimetry (micro-DSC). MicroDSC measurements were conducted with a MicroCal VP-DSC microcalorimeter. The sample concentration was always maintained at $1 \mathrm{mg} \mathrm{mL}^{-1}$. The heating and cooling rates were $1^{\circ} \mathrm{C}$ $\min ^{-1}$. Most of the measurements were done by heating the cells from $5{ }^{\circ} \mathrm{C}$ to $100{ }^{\circ} \mathrm{C}$. Prior to measurements, the cells were stabilised at $5^{\circ} \mathrm{C}$ for 10 minutes.

The reversibility of the transition was studied with controlled cooling by first stabilizing the sample at $5{ }^{\circ} \mathrm{C}$ for 10 minutes, then heating it to $75^{\circ} \mathrm{C}$ and finally cooling it back to $5{ }^{\circ} \mathrm{C}$. After the first heating and cooling cycle, the following measurements were done by varying the stabilization period, starting from the longest one. Some samples were heated only to $50{ }^{\circ} \mathrm{C}$ and cooled to $5{ }^{\circ} \mathrm{C}$ as fast as possible (in this case the cooling rate is not constant but it takes approximately 6 minutes to reach $20^{\circ} \mathrm{C}$ ). This was done in order to minimize the time spent at high temperatures.

\section{Results and discussion}

\section{Copolymerization}

A series of copolymers consisting of NIPAm and AMPTMA repeating units were synthesized, along with the corresponding homopolymers. The general structure of the polymers is given in Scheme 1.

The ratios of the repeating units and degrees of polymerization were determined by NMR spectroscopy (ESI, Fig. S1 $\dagger$ ) and listed in Table 1 . The copolymers (CPs) have been named according to their AMPTMA content as mol\%, e.g. CP-17 and CP-46 contain 17 and 46 mol\% of AMPTMA, respectively. The degrees of polymerization of the copolymers are relatively constant.

The conversions of the reactions (Table 1) were calculated by analysing the change in the integrals of the double bond signals at 5.5-5.9 ppm (ESI, Fig. S2 $\dagger$ ). The methyl protons at $1 \mathrm{ppm}$ were used as an internal standard. However, as the 


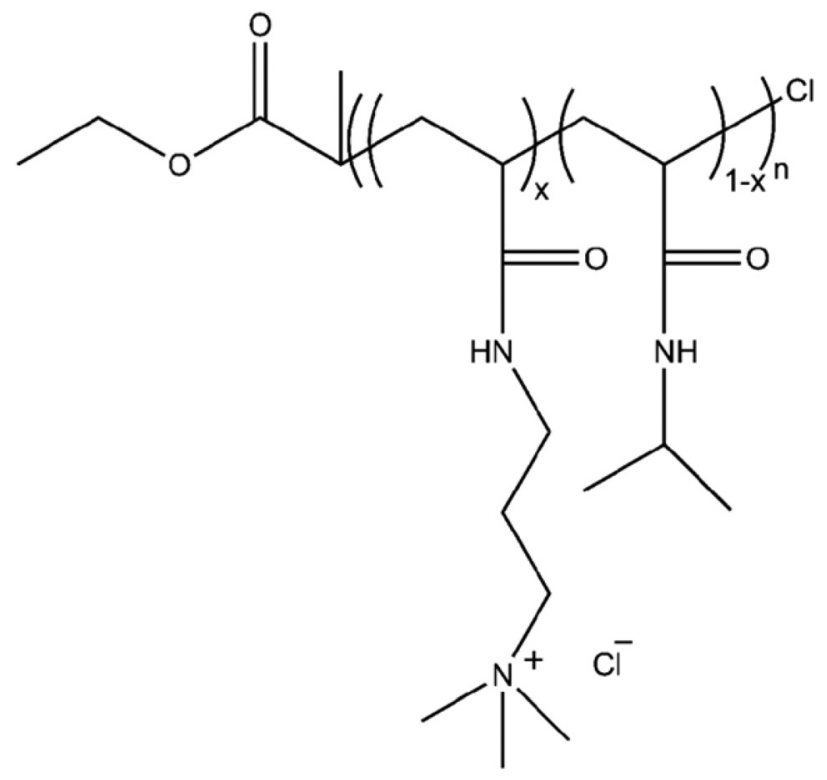

Scheme 1 The general structure of the polymers.

double bond peaks of the monomers overlap the conversions for individual monomers could not be determined. The reported values of conversion are the total conversion of all of the different double bonds in the reaction mixture.

It was observed that the AMPTMA content in the reaction mixture determined by NMR ( $f(\mathrm{NMR})$ ) was systematically lower than what could be expected from the amount of AMPTMA weighed to the reaction flask $(f(w))$. From this it can be concluded that washing with acetone and drying in a vacuum are not very effective ways to remove water from AMPTMA, which was supplied as a $75 \%$ aqueous solution (see the Materials section). However, the $f(\mathrm{NMR})$ values are in good agreement with the AMPTMA content of the final copolymers (F).

At high conversions the relative amounts of repeating units in the copolymers correspond well to the amounts in the feed.
The result as such does not give information on the randomness of the polymerization. While optimizing the reaction conditions it was observed that regardless of the ratios of monomers the AMPTMA content in the final copolymer is close to that in the feed (ESI, Fig. S3†). This also holds with varying conversions (ESI, Fig. S4 $\uparrow$ ). The results taken together indicate that the polymers may be regarded as random ones. The conclusion is important since the chain microstructure has a strong impact on the thermoresponsive properties of copolymers. ${ }^{44,57}$

Determination of the molecular weight distribution turned out to be complicated, as noted also by others for PAMPTMA containing polymers. ${ }^{58}$ SEC was conducted with two eluents and columns. First measurements were done in DMF with $1 \%$ $\mathrm{LiBr}$, and the polymer counter ions exchanged with $\mathrm{NTf}_{2}$ to improve solubility. Second measurements were run in $0.8 \mathrm{M}$ aqueous $\mathrm{NaNO}_{3}$ (see Experimental for details). Both methods gave reasonable results, see Table 1. PAMPTMA-1 and CP-65 were insoluble in DMF even after the ion exchange with $\mathrm{NTf}_{2}$, which usually improves the solubility of polycations in organic solvents. ${ }^{51}$ In the aqueous eluent, PAMPTMA-1 evidently interacts with the stationary phase since the apparent molecular weight was very low.

Molecular weight data in Table 1 are somewhat scattered, though the NMR results are close to the theoretical values. The overall conclusion is that the polymers are of the same order of molecular weights, and the distributions are sufficiently narrow.

\section{Thermal behaviour in aqueous solutions}

This study discusses polymers which show both LCST $\left(T_{\mathrm{cL}}\right)$ and UCST $\left(T_{\mathrm{cU}}\right)$ type cloud points. (For determining the $T_{\mathrm{c}} \mathrm{s}$, see Fig. S5.†) Unless otherwise noted, the values have been determined by approaching the transition from the soluble side i.e. $T_{\mathrm{cL}}$ from the heating curve and $T_{\mathrm{cU}}$ from the cooling curve. Micro-DSC was used to determine the temperature of maximum heat capacity $\left(T_{\max }\right)$ and the enthalpy associated

Table 1 NMR results and molecular weights for the studied polymers

\begin{tabular}{|c|c|c|c|c|c|c|c|c|c|}
\hline Polymer & $\begin{array}{l}f(\mathrm{w})^{a} \\
(\%)\end{array}$ & $\begin{array}{l}f(\mathrm{NMR})^{b} \\
(\%)\end{array}$ & $\begin{array}{l}F^{c} \\
(\%)\end{array}$ & $\begin{array}{l}\text { Conv. } \\
(\%)\end{array}$ & $\mathrm{DP}^{e}$ & $\begin{array}{l}M_{\mathrm{n}}(\mathrm{SEC}, \mathrm{DMF})^{f} \\
\left(\mathrm{~kg} \mathrm{~mol}{ }^{-1}\right)\left(M_{\mathrm{w}} / M_{\mathrm{n}}\right)\end{array}$ & $\begin{array}{l}M_{\mathrm{n}}(\mathrm{SEC}, \mathrm{aq} .)^{g} \\
\left.(\mathrm{~kg} \mathrm{~mol})^{-1}\right)\left(M_{\mathrm{w}} / M_{\mathrm{n}}\right)\end{array}$ & $\begin{array}{l}M_{\mathrm{n}}(\mathrm{NMR})^{h} \\
\left(\mathrm{~kg} \mathrm{~mol}{ }^{-1}\right)\end{array}$ & $\begin{array}{l}M_{\mathrm{n}}(\mathrm{th} .)^{i} \\
\left(\mathrm{~kg} \mathrm{~mol} \mathrm{~mol}^{-1}\right)\end{array}$ \\
\hline РАМРТМА-1 & 100 & 100 & 100 & 96.7 & 43.2 & Insoluble & $2.92(1.12)$ & 8.93 & 10.1 \\
\hline PNIPAm-1 & 0 & 0 & 0 & 90.4 & 69.0 & $17.5(1.28)$ & $1.36(1.07)$ & 7.94 & 10.4 \\
\hline CP-8 & 10.0 & 8.05 & 7.82 & 97.0 & 90.4 & $24.9(1.18)$ & $5.90(1.28)$ & 11.0 & 11.5 \\
\hline CP-17 & 20.1 & 18.1 & 17.1 & 90.7 & 86.2 & $28.0(1.21)$ & $10.4(1.32)$ & 11.3 & 11.6 \\
\hline CP-26 & 30.0 & 28.1 & 26.4 & 90.5 & 87.6 & $23.6(1.18)$ & $9.13(1.31)$ & 12.2 & 12.4 \\
\hline CP-46 & 50.0 & 49.5 & 46.2 & 84.8 & 79.1 & $18.0(1.16)$ & $10.0(1.26)$ & 12.5 & 13.5 \\
\hline CP-65 & 70.0 & 68.7 & 65.3 & 88.0 & 76.9 & Insoluble & 9.59 (1.19) & 13.6 & 15.0 \\
\hline
\end{tabular}

${ }^{a}$ Mole fraction of AMPTMA in the reaction mixture, based on weighing of the monomers to the reaction mixture. ${ }^{b}$ Mole fraction of AMPTMA in the reaction mixture by NMR. ${ }^{c}$ Mole fraction of AMPTMA in the copolymer by NMR. ${ }^{d}$ Total conversion, including both monomers. ${ }^{e}$ Total degree

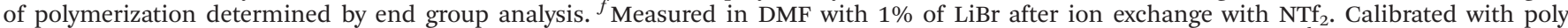
(methyl methacrylate) standards. ${ }^{g}$ Measured in $0.8 \mathrm{M}$ aqueous $\mathrm{NaNO}_{3}$. Calibrated with poly(ethylene oxide) standards. ${ }^{h} M(\mathrm{EClPr})+F \times \mathrm{DP} \times M$ $($ AMPTMA $)+(1-F) \times \mathrm{DP} \times M(\mathrm{NIPA}) .{ }^{i}$ Theoretical molecular weight: $[M(\mathrm{NIPAm}) \times$ conv. $\times n(\mathrm{NIPAm}) / n(\mathrm{EClPr})]+[M(\mathrm{AMPTMA}) \times$ conv. $\times n(\mathrm{NIPAm})$ $\times(f(\mathrm{NMR}) /(1-f(\mathrm{NMR})) / n(\mathrm{EClPr})]+M(\mathrm{EClPr})$. 
with the transition $(\Delta H)$. These values were always determined from the heating curves.

\section{Homopolymers}

When a small amount of $\operatorname{LiNTf}_{2}$ is added to aqueous PAMPTMA-1, no profound thermal transitions can be observed (ESI, Fig. S6 $\dagger$ ). If the same experiment is conducted in $100 \mathrm{mM} \mathrm{NaCl}$ a clear UCST transition appears (ESI, Fig. S7†) in the presence of $\operatorname{LiNTf}_{2}$. Similar behaviour has recently been observed with two other polycations. ${ }^{53}$

The $T_{\mathrm{cU}}$ of PAMTPMA-1 (Fig. 1) can be tuned by adjusting the concentrations of $\operatorname{LiNTf}_{2}$ and $\mathrm{NaCl}$. As can be seen from S8 in ESI, $\uparrow$ the main factor determining $T_{\mathrm{cU}}$ is the absolute concentration of $\operatorname{LiNTf}_{2}$, not the ratio between AMPTMA units and $\mathrm{NTf}_{2}$ anions. This simplifies the investigation of the copolymers in which the AMPTMA content varies. The phase separation is reversible and the transition temperatures were maintained constant when the measurement was conducted three times (ESI, Fig. S9†).

The effect of the addition of $\mathrm{LiNTf}_{2}$ and $\mathrm{NaCl}$ to the solutions of PNIPAm-1 was studied calorimetrically. Calorimetry was not employed in the case of PAMPTMA-1, because the enthalpy change of the phase separation at the UCST is more than an order of magnitude lower than that of PNIPAm at the LCST. ${ }^{59}$

Values of $T_{\max }$ (the maximum of the endothermic peak, see Fig. 2) show that increasing $\mathrm{NaCl}$ concentration decreases the transition temperature linearly, with a slope $-14.3{ }^{\circ} \mathrm{C} \mathrm{M}^{-1}$, which is in reasonable agreement with the literature values of $-13{ }^{\circ} \mathrm{C} \mathrm{M}^{-1}$ and $-10.3{ }^{\circ} \mathrm{C} \mathrm{M}^{-1} \cdot{ }^{26,29}$ Also the effect of $\mathrm{LiNTf}_{2}$ concentration is linear, and the slope is $-39.5{ }^{\circ} \mathrm{C} \mathrm{M}^{-1}$. The

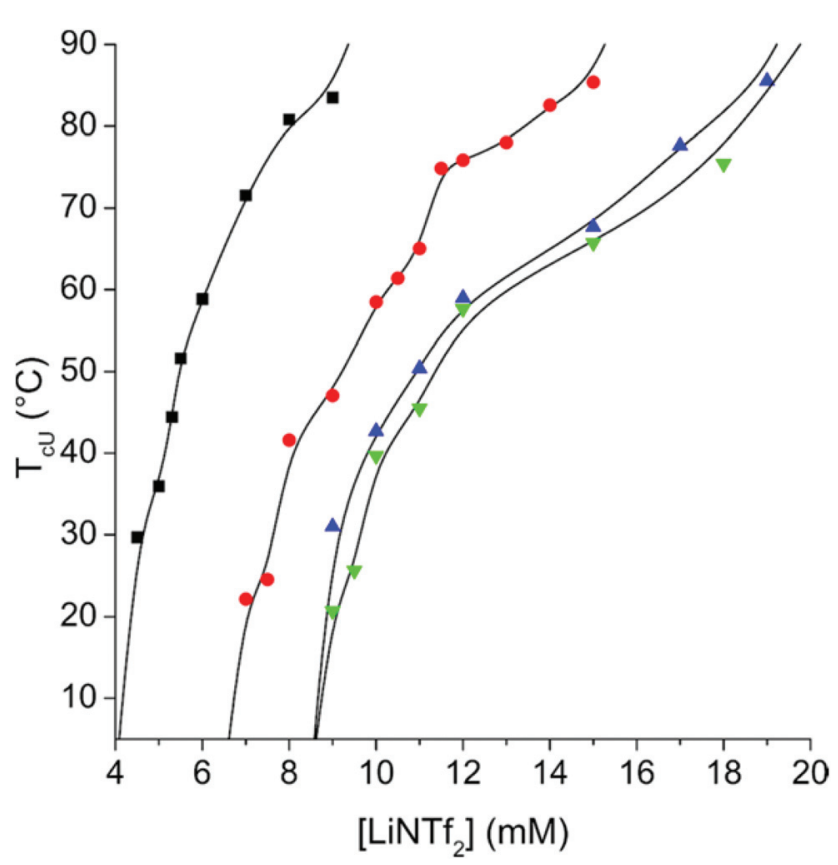

Fig. $1 T_{\mathrm{cU}}$ of $1 \mathrm{mg} \mathrm{mL}^{-1}$ solution of PAMPTMA-1 as a function of $\mathrm{LiNTf}_{2}$ concentration with $\mathrm{NaCl}$ concentrations of $100 \mathrm{mM}(\mathbf{\square}), 250 \mathrm{mM}(\bullet)$, $500 \mathrm{mM}(\mathbf{\Delta})$ and $750 \mathrm{mM}(\boldsymbol{\nabla})$. The lines are to guide the eye.

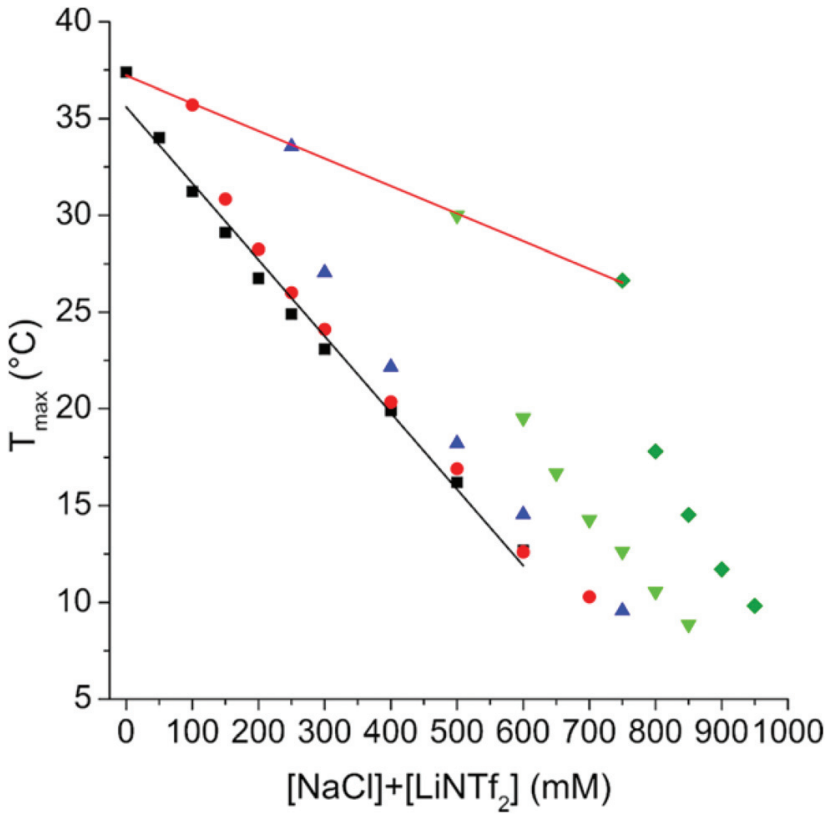

Fig. $2 T_{\max }$ as a function total concentration of salts for $1 \mathrm{mg} \mathrm{mL}^{-1}$ PNIPAM-1 solutions containing $\mathrm{LiNTf}_{2}$ with no added $\mathrm{NaCl}(\boldsymbol{\square})$, with $100 \mathrm{mM} \mathrm{NaCl}(\bullet)$, with $250 \mathrm{mM} \mathrm{NaCl}(\boldsymbol{\Delta})$, with $500 \mathrm{mM} \mathrm{NaCl}(\boldsymbol{\nabla})$ and with $750 \mathrm{mM} \mathrm{NaCl}(\diamond)$. The black line marks a linear fit for the solutions with only $\mathrm{LiNTf}_{2}$ and red line for the ones with only $\mathrm{NaCl}$.

highly negative slope of $\operatorname{LiNTf}_{2}$ is of the same order as the slopes of the strongest kosmotropes of the Hofmeister series, like $\mathrm{NaSO}_{4}$, which has a slope between -33.7 and $-38.0{ }^{\circ} \mathrm{C}$ $\mathrm{M}^{-1}$, depending on the molecular weight of PNIPAm. ${ }^{29}$

The salts have a synergistic effect since the $T_{\max }$ decreases faster in the case of mixtures than it does with either salt alone. In the case of the present pair of salts, the contributions of individual ions, as is the case with potassium halides, cannot be distinguished. ${ }^{26}$ The enthalpy associated with the PNIPAm phase separation is practically constant with the $\mathrm{NaCl}$ concentration, but decreases heavily when LiNTf $_{2}$ is introduced (ESI, Fig. S10†).

Some representative thermograms of PNIPAm- 1 are shown in ESI (Fig. S11†). Comparison of Fig. 1 and 2 reveals that LiNTf $_{2}$ concentration has a much stronger effect on the transition temperature of PAMPTMA-1 than on PNIPAm-1. The observation indicates that the effect of $\operatorname{LiNTf}_{2}$ on the copolymers arises completely from interactions between AMPTMA units and $\mathrm{NTf}_{2}$ ions.

\section{Copolymers}

The $T_{\mathrm{cL}}$ of CP-17 in varying $\mathrm{NaCl}$ concentrations can be altered within a broad range of temperatures by altering the $\operatorname{LiNTf}_{2}$ concentration (Fig. 3). LiNTf $_{2}$ "switches off" the AMPTMA charges and thus the polymer becomes a PNIPAm copolymer, the hydrophilic/hydrophobic ratio of which can be varied after the polymerization. The adjustment of the ionic strength is crucial to screen the charges in the mixture. At a NaCl concentration of $750 \mathrm{mM}$ the ionic strength is high enough to screen 


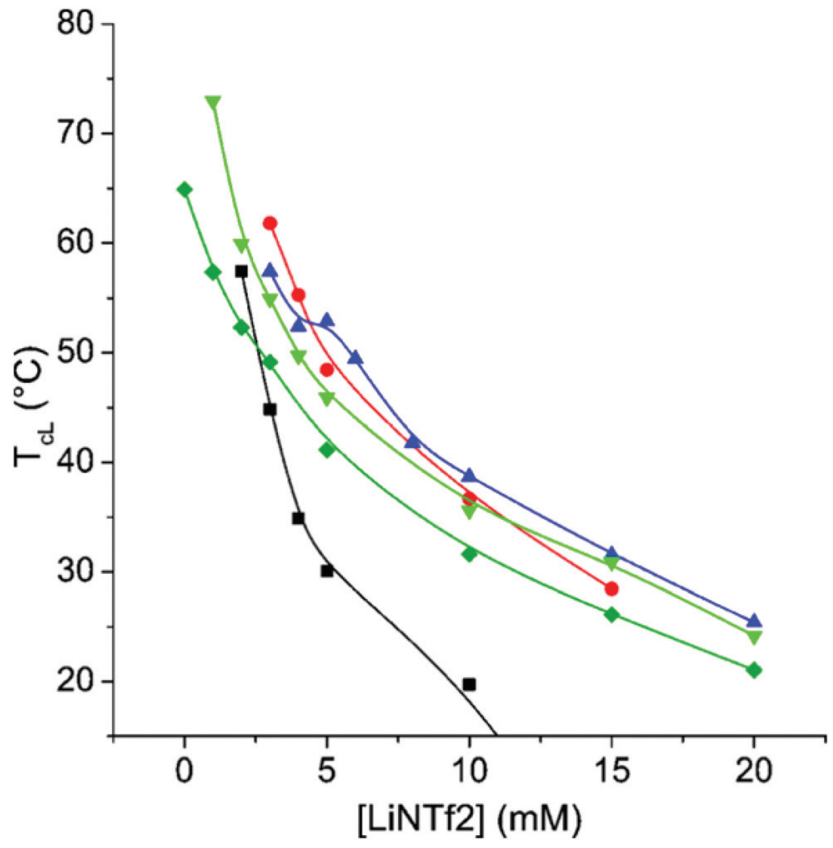

Fig. $3 T_{\mathrm{cL}}$ of $1 \mathrm{mg} \mathrm{mL}^{-1}$ solution of CP-17 as a function of LiNTf 2 concentration with no added $\mathrm{NaCl}(\square)$, with $100 \mathrm{mM} \mathrm{NaCl}(\bullet)$, with $250 \mathrm{mM}$ $\mathrm{NaCl}(\boldsymbol{\Delta})$, with $500 \mathrm{mM} \mathrm{NaCl}(\boldsymbol{\nabla})$, and with $750 \mathrm{mM} \mathrm{NaCl}(\diamond)$. The lines are to guide the eye.

the charges so effectively that $T_{\mathrm{cL}}$ is observable even without any $\operatorname{LiNTf}_{2}$. This effectively sets an upper limit to $T_{\mathrm{cL}}$.

The results for CP-8 and CP-26 are qualitatively the same (ESI, Fig. S12 and S13 $\dagger$ ). The major difference is that with CP-8, $250 \mathrm{mM} \mathrm{NaCl-concentration} \mathrm{is} \mathrm{enough} \mathrm{for} \mathrm{the} \mathrm{detection}$ of $T_{\mathrm{c}}$ without any $\operatorname{LiNTf}_{2}$, but with CP-26 not even $750 \mathrm{mM}$ is enough for this. This is in line with the results of Soll et al. who studied copolymers of NIPAm and a cationic monomer in various concentrations of $\mathrm{KBr}^{54}$ Due to electrostatic interactions, the transitions are broad even at $500 \mathrm{mM} \mathrm{NaCl}$ (ESI, Fig. S14 $\dagger$ ). The transition gets narrower with increasing concentrations of $\operatorname{LiNTf}_{2}$, indicating effective ion pairing and therefore "switching off" the charges. The $T_{\mathrm{cL}}$ is fairly independent of the polymer concentration (ESI, Fig. S15 †).

Altogether, the results with CP-8, CP-17, and CP-26 show that with these copolymers, the $T_{\mathrm{cL}}$ is adjustable over a broad range of concentrations using $\mathrm{NaCl}$ and $\operatorname{LiNTf}_{2}$.

The enthalpy changes associated with the dehydration of NIPAm units upon thermal transition decrease with increasing transition temperature (Fig. 4). The results of the calorimetric measurements show similar trends as the turbidity measurements discussed above (ESI, Fig. S16-18†).

As CP-46 contains nearly equal amounts of the two different repeating units its phase separation characteristics show features of the corresponding homopolymers (Fig. 5). Evidently the ion pairing decreases the electrostatic repulsion at low temperatures, but when temperature increases the ion pairs start to dissociate. Thus, at high temperatures the electrostatic interactions overrule the hydrophobic ones and

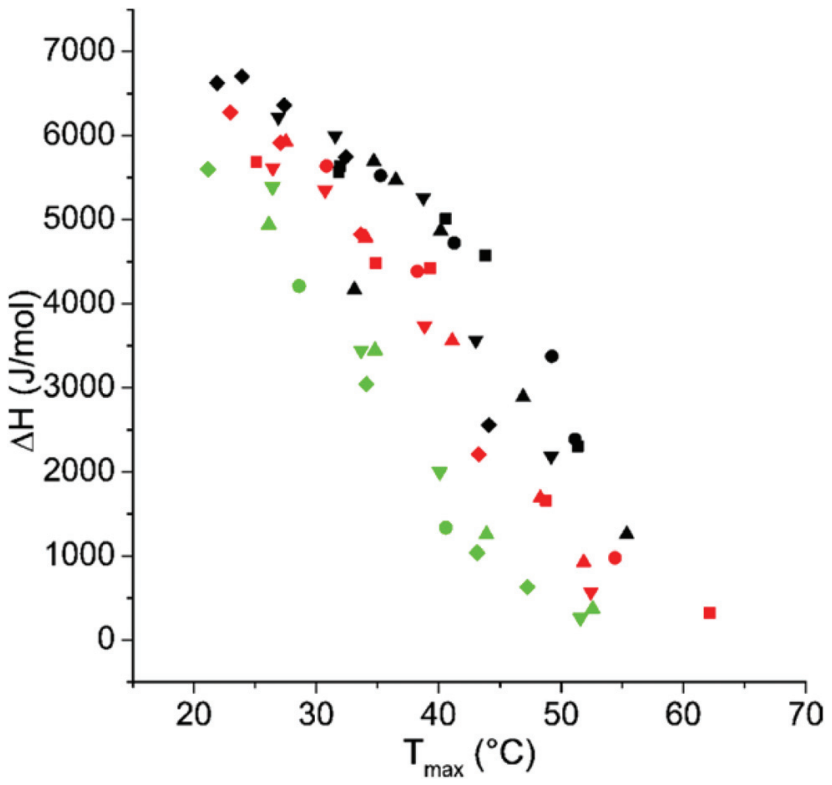

Fig. $4 \Delta H$ as a function of $T_{\max }$ for CP-8 (black), CP-17 (red), and CP-26 (green) with no added $\mathrm{NaCl}(\square)$, with $100 \mathrm{mM} \mathrm{NaCl}(\bullet)$, with $250 \mathrm{mM} \mathrm{NaCl}(\boldsymbol{\Delta})$, with $500 \mathrm{mM} \mathrm{NaCl}(\boldsymbol{\nabla})$, or with $750 \mathrm{mM} \mathrm{NaCl}(\diamond)$. The enthalpies are reported per mole of NIPAm units.

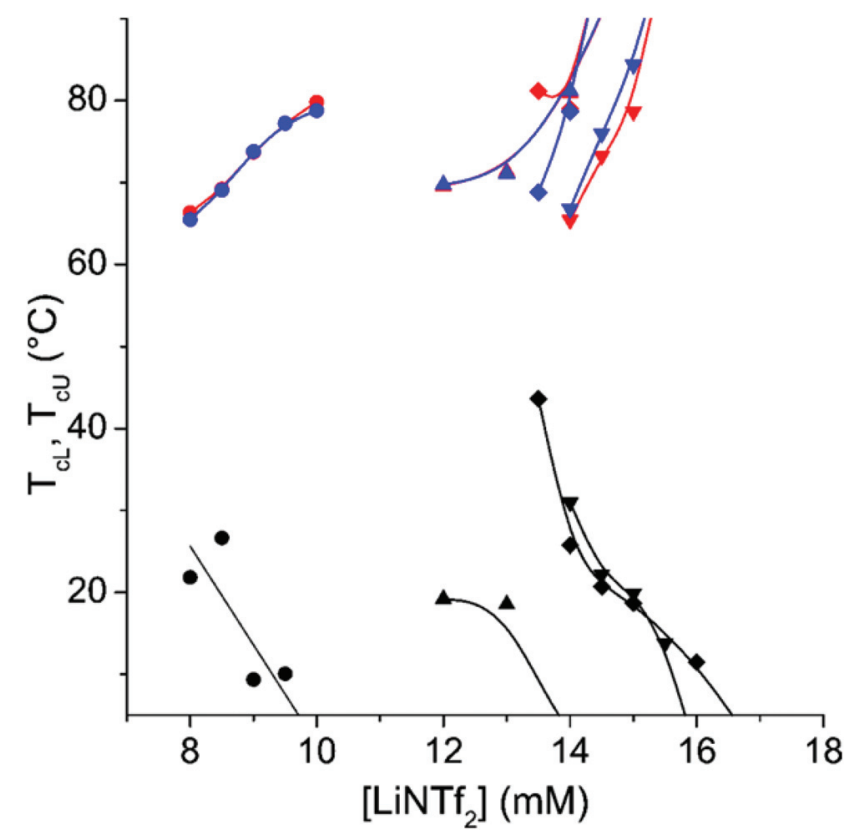

Fig. $5 T_{\mathrm{CL}}$ (black), $T_{\mathrm{cU}}$ on heating (red) and $T_{\mathrm{CU}}$ on cooling (blue) as a function of $\mathrm{LiNTf}_{2}$ concentration for CP-46 in $100 \mathrm{mM} \mathrm{NaCl}(\bullet)$, $250 \mathrm{mM} \mathrm{NaCl}(\boldsymbol{\Delta}), 500 \mathrm{mM} \mathrm{NaCl}(\boldsymbol{\nabla})$, and $750 \mathrm{mM} \mathrm{NaCl}(\diamond)$. The lines are to guide the eye. The measurements were started by heating runs from 5 to $90{ }^{\circ} \mathrm{C}$, followed by cooling runs from 90 to $5{ }^{\circ} \mathrm{C}$ (see Experimental for details).

this leads to the redissolution of the polymer. As a result the polymer shows both $T_{\mathrm{cL}}$ and $T_{\mathrm{cU}}$ in NaCl containing solutions. Only very wide transitions can be observed in a solution 


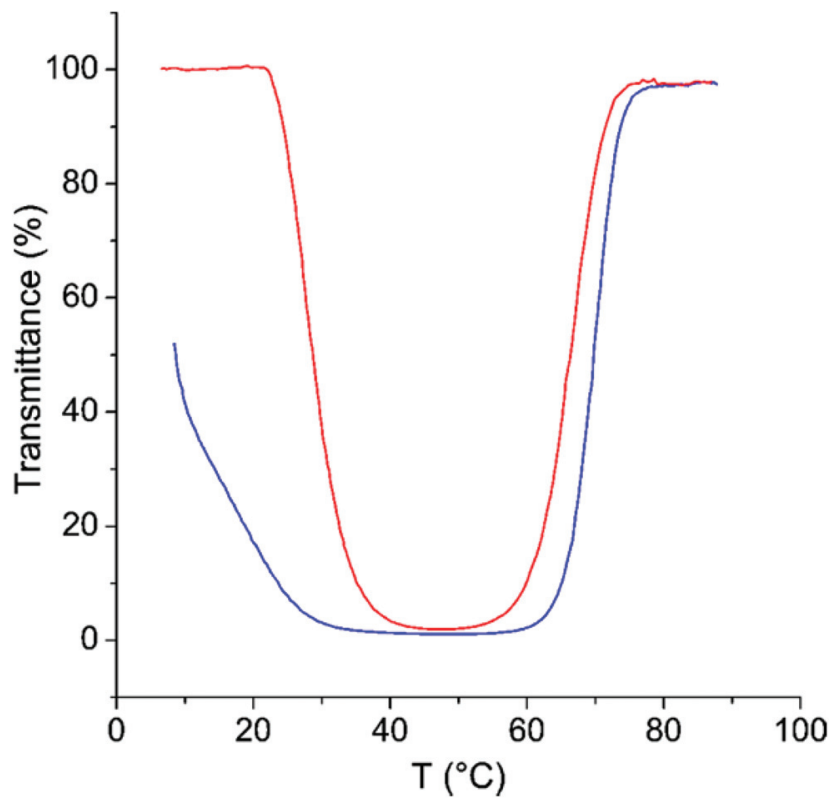

Fig. 6 Transmittance as a function of temperature on heating (red) and on cooling (blue) for CP-46 in $500 \mathrm{mM} \mathrm{NaCl}$ with $14.5 \mathrm{mM} \mathrm{LiNTf}_{2}$.

without NaCl. The concentration range of $\operatorname{LiNTf}_{2}$ between complete solubility and complete insolubility is narrow, less than $4 \mathrm{mM}$ in each case. The temperature range in which CP-46 is insoluble narrows as the polymer concentration decreases (ESI, Fig. S19†). Owing to the low NIPAm content of CP-46, the phase separation could not be observed calorimetrically.

As can be seen in Fig. 5, the phase separation at the $T_{\mathrm{cU}}$ shows only minimal hysteresis. On the other hand, the hysteresis in the process occurring at $T_{\mathrm{cL}}$ is very strong (Fig. 6). Longenecker et al. have observed similar behaviour for copolymers of hydroxyethyl methacrylate and a methacrylamide analogue of AMPTMA. ${ }^{50}$ They attribute this to the formation of hydrogen bonds, which probably is the case also with the copolymer of NIPAm and AMPTMA.

The formation of hydrogen bonds is known to be the reason for the hysteresis for the PNIPAm homopolymer. ${ }^{23}$ The much more pronounced hysteresis in the present case can be rationalized by the fact that AMPTMA units with $\mathrm{NTf}_{2}$ ions are hydrophobic at low temperatures and thus are more likely to remain hydrogen bound to NIPAm units instead of forming hydrogen bonds with water. The formation of complexes between the cationic groups of AMPTMA and amides of NIPAm in the collapsed state cannot be ruled out either.

The AMPTMA content of CP-65 is so high that the polymer behaves as PAMPTMA-1 (Fig. 7). The polymer displays only $T_{\mathrm{cU}}$, which indicates that at low temperatures the solubility of PNIPAm is not sufficient to dissolve CP-65 in the presence of the added salts. The hysteresis upon the heating and cooling cycles is very small. Interestingly, comparison of Fig. 1 and 7 shows that $T_{\mathrm{cU}}$ of PAMPTMA-1 is always higher than $T_{\mathrm{cU}}$ of CP-65, when the NaCl and $\operatorname{LiNTf}_{2}$ concentrations are the same.

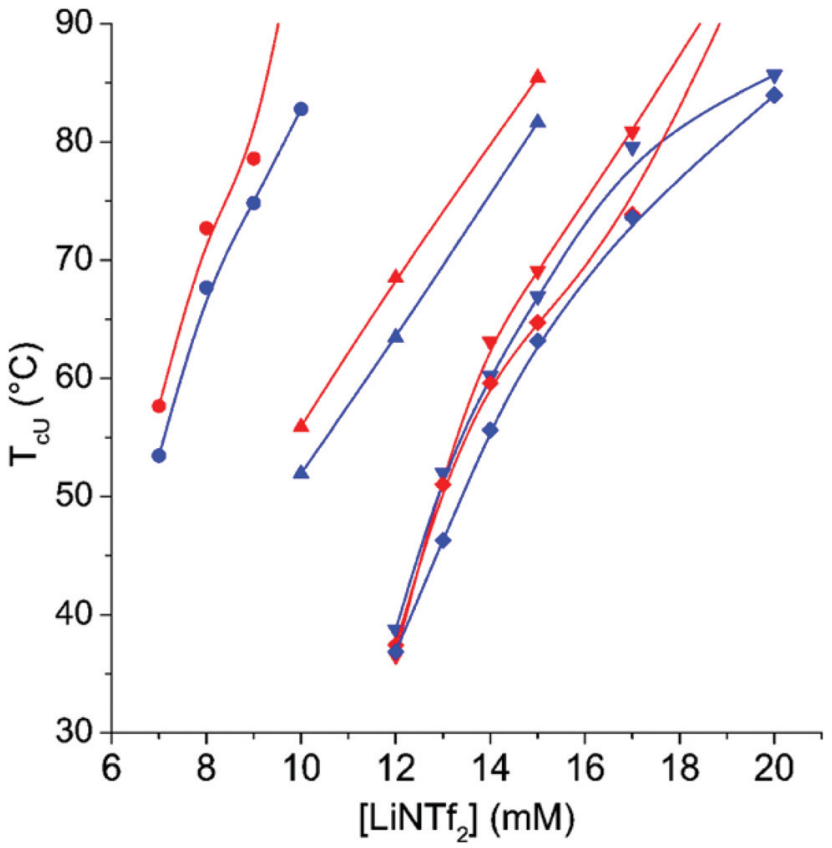

Fig. $7 T_{\mathrm{cU}}$ on heating (red) and $T_{\mathrm{cU}}$ on cooling (blue) as a function of $\mathrm{LiNTf}_{2}$ concentration for CP-65 in $100 \mathrm{mM} \mathrm{NaCl}(\bullet), 250 \mathrm{mM} \mathrm{NaCl}(\boldsymbol{\Delta})$, $500 \mathrm{mM} \mathrm{NaCl}(\nabla)$, and $750 \mathrm{mM} \mathrm{NaCl}(\diamond)$. The lines are to guide the eye. The measurements were started by heating runs from 5 to $90{ }^{\circ} \mathrm{C}$, followed by cooling runs from 90 to $5{ }^{\circ} \mathrm{C}$ (see Experimental for details).

In the CP-65-NTf ${ }_{2}$ system, NIPAm units seem to increase polymer solubility even at elevated temperatures.

Finally, a note on the reversibility of the transitions needs to be added. CP-46 did not show complete redissolution upon controlled cooling, as can be seen in Fig. 6. In general, addition of salts slowed down remixing. For PNIPAm-1 this was observed in $500 \mathrm{mM} \mathrm{NaCl}$ and for CP-8 in $10 \mathrm{mM} \mathrm{LiNTf}_{2}$ (ESI, Fig. S20 and S21 $\uparrow$ ). A clear shoulder could be observed in the endotherms, and it did not totally vanish upon stabilizing the samples for 16 hours at $5{ }^{\circ} \mathrm{C}$. However, when the time the sample was kept above $T_{\text {cL }}$ was minimized (ESI, Fig. S22 and $\mathrm{S} 23 \dagger)$, or when the sample was quenched to the starting temperature, the system was completely reversible (Fig. S24†).

The slower redissolution of PNIPAm-1 in the salt solution is due to the poorer solvent quality of $500 \mathrm{mM} \mathrm{NaCl}$ for PNIPAm compared to pure water, and this is why the $T_{\max }$ is also lower. It is known from PNIPAm in water that the redissolution slows down when the polymer is kept above its transition temperature for long. ${ }^{24}$ This is also the case for the present polymers and is probably due to the fact that intra- and intermolecular hydrogen bonds have more time to form.

\section{Conclusions}

Copolymers of NIPAm and cationic AMPTMA were successfully synthesized. The ratios of repeating units in the copolymers were similar to those in the feed. The determination of 
molecular weights proved to be difficult, but the polymers were of equal size and the molecular weights were narrowly distributed.

The introduction of $\operatorname{LiNTf}_{2}$ to the solution of PAMPTMA-1 turned the polymer insoluble in water and a UCST type behaviour was observed when $\mathrm{NaCl}$ was also present in the solution. This is probably due to the ion pairing which is reversed at high temperatures. A sufficiently high concentration of $\mathrm{NaCl}$ is required to screen the charges in a way that the AMPTMA units and $\mathrm{NTf}_{2}$ ions do not "sense" each other, and the polymer dissolves. The competition between $\mathrm{NTf}_{2}$ and chloride ions of the cationic sites in the polymer made PAMPTMA-1 less sensitive to LiNTf $_{2}$ at higher $\mathrm{NaCl}$ concentrations. The UCST behaviour as described above is reported for the first time for this particular pair of ions.

For PNIPAm, it was shown that $\operatorname{LiNTf}_{2}$ has an effect similar to the strongest kosmotropes in the Hofmeister series, seen as the strong transition temperature lowering effect of $\operatorname{LiNTf}_{2}$. Although the effect of $\operatorname{LiNTf}_{2}$ on the transition temperature of PNIPAm is strong, its effect on PAMPTMA is much stronger. Thus the effect of $\operatorname{LiNTf}_{2}$ on the copolymers arises mostly from the interactions between AMPTMA units and $\mathrm{NTf}_{2}$ ions.

The charges in the copolymers with a low AMPTMA content could be "switched off" with $\operatorname{LiNTf}_{2}$ due to the ion pairing. The addition of the bulky hydrophobic $\mathrm{NTf}_{2}$ anion to the copolymer solution is analogous to a case where NIPAm is copolymerized with a hydrophobic monomer. However, in the present case the "comonomer content" can be manipulated after the polymerization. As with the homopolymer PAMPTMA-1, the strength of the effect of $\operatorname{LiNTf}_{2}$ on the copolymer $T_{\mathrm{cL}}$ is modulated by the presence of $\mathrm{NaCl}$. In several cases the phase remixing was slow, which can be attributed to hydrogen and ionic bonds in the collapsed state.

When the AMPTMA content of the copolymer is sufficiently high, both LCST and UCST transitions occur. With the highest AMPTMA content, 65 mol\%, only UCST could be observed, however, with less sensitivity towards $\operatorname{LiNTf}_{2}$ than was the case with the PAMPTMA-1 homopolymer.

In short, a new method has been developed to adjust the phase transition temperature(s) of NIPAm-containing copolymers. This should be also generally applicable to several thermosensitive copolymers that contain cationic units.

\section{Acknowledgements}

Financial support from the Academy of Finland (grant number 264990) and ERA.Net RUS (Project SILICAMPS) is gratefully acknowledged.

\section{References}

1 J. Seuring and S. Agarwal, Macromol. Rapid Commun., 2012, 33, 1898-1920.
2 M. Heskins and J. E. Guillet, J. Macromol. Sci., Chem., 1968, 2, 1441-1455.

3 V. Aseyev, H. Tenhu and F. M. Winnik, Adv. Polym. Sci., 2011, 242, 29-89.

4 S. Fujishige, K. Kubota and I. Ando, J. Phys. Chem., 1989, 93, 3311-3313.

5 Y. Xia, X. Yin, N. A. D. Burke and H. D. H. Stöver, Macromolecules, 2005, 38, 5937-5943.

6 Y. Xia, N. A. D. Burke and H. D. H. Stöver, Macromolecules, 2006, 39, 2275-2283.

7 K. Kubota, S. Fujishige and I. Ando, J. Phys. Chem., 1990, 94, 5154-5158.

8 P. Kujawa, V. Aseyev, H. Tenhu and F. M. Winnik, Macromolecules, 2006, 39, 7686-7693.

9 H. G. Schild and D. A. Tirrell, J. Phys. Chem., 1990, 94, 4352-4356.

10 Y. Maeda, T. Higuchi and I. Ikeda, Langmuir, 2000, 16, 7503-7509.

11 Y. Maeda, T. Nakamura and I. Ikeda, Macromolecules, 2001, 34, 1391-1399.

12 S. A. Deshmukh, S. K. R. S. Sankaranarayanan, K. Suthar and D. C. Mancini, J. Phys. Chem. B, 2012, 116, 2651-2663.

13 C. Wu and S. Zhou, Macromolecules, 1995, 28, 5388-5390.

14 C. Wu and X. Wang, Phys. Rev. Lett., 1998, 80, 4092-4094.

15 X. Wang, X. Qiu and C. Wu, Macromolecules, 1998, 31, 2972-2976.

16 E. I. Tiktopulo, V. E. Bychkova, J. Ricka and O. B. Ptitsyn, Macromolecules, 1994, 27, 2879-2882.

17 E. I. Tiktopulo, V. N. Uversky, V. B. Lushchik, S. I. Klenin, V. E. Bychkova and O. B. Ptitsyn, Macromolecules, 1995, 28, 7519-7524.

18 J. Heyda and J. Dzubiella, J. Phys. Chem. B, 2014, 118, 10979-10988.

19 Y. Maeda, T. Higuchi and I. Ikeda, Langmuir, 2001, 17, 7535-7539.

20 T. Principi, C. C. E. Goh, R. C. W. Liu and F. M. Winnik, Macromolecules, 2000, 33, 2958-2966.

21 H. G. Schild and D. A. Tirrell, Langmuir, 1991, 7, 665-671.

22 B. Sun, Y. Lin, P. Wu and H. W. Siesler, Macromolecules, 2008, 41, 1512-1520.

23 H. Cheng, L. Shen and C. Wu, Macromolecules, 2006, 39, 2325-2329.

24 K. Van Durme, G. Van Assche and B. Van Mele, Macromolecules, 2004, 37, 9596-9605.

25 H. Lai, Q. Chen and P. Wu, Soft Matter, 2013, 9, 39853993.

26 R. Freitag and F. Garret-Flaudy, Langmuir, 2002, 18, 34343440.

27 Y. Zhang, S. Furyk, D. E. Bergbreiter and P. S. Cremer, J. Am. Chem. Soc., 2005, 127, 14505-14510.

28 Y. Zhang and P. S. Cremer, Curr. Opin. Chem. Biol., 2006, 10, 658-663.

29 Y. Zhang, S. Furyk, L. B. Sagle, Y. Cho, D. E. Bergbreiter and P. S. Cremer, J. Phys. Chem. C, 2007, 111, 8916-8924.

30 I. Shechter, O. Ramon, I. Portnaya, Y. Paz and Y. D. Livney, Macromolecules, 2010, 43, 480-487. 
31 H. Du, R. Wickramasinghe and X. Qian, J. Phys. Chem. B, 2010, 114, 16594-16604.

32 F. Kohori, K. Sakai, T. Aoyagi, M. Yokoyama, Y. Sakurai and T. Okano, J. Controlled Release, 1998, 55, 87-98.

33 S. Furyk, Y. Zhang, D. Ortiz-Acosta, P. S. Cremer and D. E. Bergbreiter, J. Polym. Sci., Part A: Polym. Chem., 2006, 44, 1492-1501.

34 M. Ito and T. Ishizone, J. Polym. Sci., Part A: Polym. Chem., 2006, 44, 4832-4845.

35 B. Ray, Y. Okamoto, M. Kamigaito, M. Sawamoto, K. Seno, S. Kanaoka and S. Aoshima, Polym. J., 2005, 37, 234237.

36 T. Hirano, Y. Okumura, H. Kitajima, M. Seno and T. Sato, J. Polym. Sci., Part A: Polym. Chem., 2006, 44, 44504460.

37 F. M. Winnik, H. Ringsdorf and J. Venzmer, Macromolecules, 1990, 23, 2415-2416.

38 H. G. Schild, M. Muthukumar and D. A. Tirrell, Macromolecules, 1991, 24, 948-952.

39 H. Feil, Y. H. Bae, J. Feijen and S. W. Kim, Macromolecules, 1993, 26, 2496-2500.

40 Y. G. Takei, T. Aoki, K. Sanui, N. Ogata, T. Okano and Y. Sakurai, Bioconjugate Chem., 1993, 4, 341-346.

41 Z. Shen, K. Terao, Y. Maki, T. Dobashi, G. Ma and T. Yamamoto, Colloid Polym. Sci., 2006, 284, 1001-1007.

42 J. E. Chung, M. Yokoyama, T. Aoyagi, Y. Sakurai and T. Okano, J. Controlled Release, 1998, 53, 119-130.

43 H. Liu, D. Avoce, Z. Song and X. X. Zhu, Macromol. Rapid Commun., 2001, 22, 675-680.

44 Y. Weng, Y. Ding and G. Zhang, J. Phys. Chem. B, 2006, 110, 11813-11817.
45 T. Maeda, K. Yamamoto and T. Aoyagi, J. Colloid Interface Sci., 2006, 302, 467-474.

46 Y. Maeda, H. Yamamoto and I. Ikeda, Langmuir, 2001, 17, 6855-6859.

47 G. Bokias, G. Staikos and I. Iliopoulos, Polymer, 2000, 41, 7399-7405.

48 T. Mori, M. Nakashima, Y. Fukuda, K. Minagawa, M. Tanaka and Y. Maeda, Langmuir, 2006, 22, 4336-4342.

49 J. Fang, F. Bian and W. Shen, J. Appl. Polym. Sci., 2008, 110, 3373-3378.

50 R. Longenecker, T. Mu, M. Hanna, N. A. D. Burke and H. D. H. Stöver, Macromolecules, 2011, 44, 8962-8971.

51 R. Marcilla, J. A. Blazquez, R. Fernandez, H. Grande, J. A. Pomposo and D. Mecerreyes, Macromol. Chem. Phys, 2005, 206, 299-304.

52 E. Karjalainen, V. Aseyev and H. Tenhu, Macromolecules, 2014, 47, 2103-2111.

53 E. Karjalainen, V. Aseyev and H. Tenhu, Macromolecules, 2014, 47, 7581-7587.

54 S. Soll, M. Antonietti and J. Yuan, ACS Macro Lett., 2012, 1, 84-87.

55 S. Strandman, P. Pulkkinen and H. Tenhu, J. Polym. Sci., Part A: Polym. Chem., 2005, 43, 3349-3358.

56 J. Wang and K. Matyjaszewski, J. Am. Chem. Soc., 1995, 117, 5614-5615.

57 B. A. Pineda-Contreras, F. Liu and S. Agarwal, J. Polym. Sci., Part A: Polym. Chem., 2014, 52, 1878-1884.

58 E. V. Korchagina, X. Qiu and F. M. Winnik, Macromolecules, 2013, 46, 2341-2351.

59 J. Seuring, F. M. Bayer, K. Huber and S. Agarwal, Macromolecules, 2012, 45, 374-384. 